\title{
The Impact of Oil Prices on the U.S. Stock Market
}

\author{
Congqi Bai ${ }^{1, *, \dagger}$, Chenglin Gong ${ }^{2, *, \dagger}$, Ziyang $\mathrm{Qiu}^{3, *, \dagger}$, Yingjie Sheng ${ }^{4, *}, \dagger$, Tong $\mathrm{Wu}^{5,{ }^{*}, \dagger}$ \\ ${ }^{1}$ Harbin No.3 High School, Harbin,150000, China \\ 2 Jiangsu Tianyi High School,Wuxi, 214000, China \\ ${ }^{3}$ Hurtwood House School, Surrey, RH5 6NU, United Kingdom \\ ${ }^{4}$ Juan Diego Catholic High School, Draper, UT 84020, United States \\ ${ }^{5}$ Robert Louis Stevenson School, Pebble Beach, CA 93953, United States \\ *Corresponding author.Email: awu23@stevensonschool.org \\ These authors contributed equally.
}

\begin{abstract}
Oil is closely related to the world economy and is one of the most important materials in the commodity market. Its price fluctuation can directly affect the supply of the oil market, thus affecting world inflation. The US stock market can more reflect the world profit level and economic indicators. They are the key components of the world economy and an interesting research area, so we conducted this research. This study analysis and compare historical data of oil price and the U.S. stock market return. The price of crude oil does not affect the stock market directly, but it does affect U.S. stocks through indirect transmission. The analysis indicates that the oil price has little influence when it is stable, but it has more influence when it is volatile. A correlation can arise because changes in the crude oil price rate affect the outlook for a firm's corporate profits and therefore affect the U.S. stock market performance. In addition, crude oil prices affect CPI and PPI, a leading measure of inflation, which in turn affects U.S. interest rates and corresponding affecting the US stock market.
\end{abstract}

Keywords: Oil prices, Stock returns, U.S. Stock Market

\section{INTRODUCTION}

\subsection{Background}

The fluctuation of oil prices and their impact have long attracted the attention of researchers. They analyse such impact on industries, countries, and economic activities. Lutz and Cheolbeom examine the association between the cause of oil price shock and its impact on different industries [1]. Hedi et al. suggested that each sector of a stock market could respond differently to the change in oil price [2]. Syed and Zwick studied the US stock market and concluded that the impact between stock markets and oil prices could be positive and negative [3]. Demirer et al. concluded that oil prices impacted both the stock market and the bond markets. Le et al. found that the markets of Japan, Singapore, Korea, and Malaysia respond to oil price fluctuations in different ways [4]. During COVID-19, many researchers focus on the effect of COVID-19 pandemics on oil price and the stock market. Hence, the oil price is significant to the market and economy. In hoping to identify the cause of the association between oil price and the stock market and the relationship between the oil price and stock market, evidence is gathered to analyse the impact of oil price on the market.

\subsection{Related Research}

The relationship between oil price and the stock market draws the interest of many researchers. Lutz and Cheolbeom found that the stock market return may differ depending on the cause of the oil price shock. For example, only when oil demand shocks, such as the demand due to fear for future oil availability, occur, negative stock price response is associated with the oil price. On the other hand, if the cause of oil price rise is global economic expansion, the stock return demonstrates a positive response. Under the two above circumstances, different industries were impacted. For example, if oil price rises due to demand, petroleum, natural gas, gold, and silver mining industries undergo positive responses; and the automobile industry and the retail sector experience negative responses. On the other hand, if a global economic expansion is an underlying cause for the oil price increase, all five industries 
mentioned above will have positive returns [1]. Some researchers also utilize historical data to analyse the longterm pattern. Syed and Zwick separately analysed the oil price and stock market in the US economy from 1980 and 2016 and found a non-linear relationship between oil price and the stock market. The author justifies the accuracy of the previous research, showing that the relation between oil price and the stock market could be positive or negative in the different conditions. The author concludes that the impact of the oil price on economic activity is often according to the economic overall macroeconomic conditions [3]. Hedi et al. extend the understanding of oil-stock market relationships over the last turbulent decade. Unlike previous empirical investigations, which have largely focused on broadbased market indices (national and/or regional indices), we examine short-term linkages in the aggregate and sector by sector levels in Europe using different econometric techniques. Our main findings suggest that the reactions of stock returns to oil price changes differ greatly depending on the activity sector. In the out-ofsample analysis, we show that introducing oil assets into a diversified portfolio of stocks significantly improves its risk-return characteristics [2]. Sim and Zhou examine the relationship between oil prices and US equities by proposing a Quantile-on-Quantile (QQ) approach that is suitable for estimating the effect of oil price shocks have on the quantiles of the US stock return. It is richer than is possible with OLS or quantile regression for economic modelling. This approach can uncover some features in the relationship between US equities and oil prices. By offering some evidence, they show that the level of dependence between Oil and equities could be distribution-specific. And they use the insight that the combination of quantile and local linear regression. The QQ approach is a general method that can estimate and detect complex features that other economic frameworks may not handle, particularly the relationship between stocks and oil prices [5]. Heidari et al. investigates the effect of different types of oil price shocks on the timevarying correlation between oil and stock markets and compares this effect in the oil importer and oil exporter countries for the period of 1996:1-2014:2. To this end, the paper uses SVAR, cDCC and MS models introduced by Kilian (2009), Aielli (2011) and Hamilton (1989), respectively. These models help us to apply nonlinear and dynamic linkages in estimating the relationship between oil price shocks and the correlations between oil and stock markets. Our results show that the correlation between oil and stock markets does not depend on oil price shocks origins and being oil importer or oil exporter countries. We also conclude that the relationship between oil price returns and stock index returns are time-varying for selected countries. Considering the results, it is obvious that international investors could not hedge oil price shocks' risks in their global portfolio by diversification and managing their portfolio of oil importer and oil exporter stock markets. Hence, it is suggested they use other substituted policies and investing strategies, like future contracts [6]. Mohanty et al. studied the critical importance of oil to the rest of the world economy. They used equity returns data for both country-level and sector-level to assess the relationship between crude oil price fluctuations and equity returns in the Gulf Cooperation Council countries. The finding shows a significant positive relation between oil price changes and stock market returns in GCC countries, except for Kuwait, during the June 2005-December 2009 period. There are significant differences in the response of industry returns to oil price shocks within the GCC region at the industry level. 12/20 industries in the GCC countries have significant positive exposures to oil shocks in that specific period. Finally, research shows that oil price volatilities have asymmetric effects on stock market returns at the country and industry levels [7].

Besides the impact of oil price on different markets, researchers' attention has centered on the oil price and its impacts during COVID-19. Mohammed et al. researched the relationship between the COVID-19 pandemic and oil price by using the autoregressive distributed lag (ARDL) model and vector error correction (VECM) model. Researchers depended on the phenomenon that the oil price decreased in a fluctuant from 20th January 2020 to 31 st March 2020. In the end, the researchers concluded that in the short run, the crude oil price is negatively and significantly related to COVID-19 [8]. Other researchers utilized data from the UK stock market to analyse the impact of oil prices during COVID-19. Mugaloglu et al. researched during Covid-19 the impact of oil prices on the stock market. They used the FTSE100 index as a proxy for the UK stock market and Brent as a proxy for global oil prices. His research used the relationship between the UK stock market and global oil price to calculate the impact on the stock market during Covid-19. After passing a series of data comparisons, a conclusion is drawn. Although the oil price has dropped during the Covid and the stock market also experienced some volatility, compared with previous data from Covid, the global oil price is not very important to the UK stock market [9].

The fluctuation of oil price also has a profound impact on aspects besides the stock market, and it impacts different markets and different parts of a market differently. Demirer et al. found that oil prices impacted the stock market and the bond market by investigating oil prices and financial market data. This research explores the relationship between oil prices and the stock market and also proves that oil has a global financial connectivity model. After comparing stocks and securities data in many different regions, they confirmed that global stocks and bonds respond differently to oil price shocks. It depends on the reason. This research analyses that the oil price shock has a certain relationship with the stock and bond market depending on the economic characteristics of each country. If a country's economy is not very strong, 
then the impact of oil prices on the financial market is huge [4]. Le et al. examines the response of stock markets to oil price volatilities in Japan, Singapore, Korea, and Malaysia by applying the generalized impulse response and variance decomposition analyses to the monthly data spanning 1986:01 - 2011:02. The results suggest that the reaction of stock markets to oil price shocks varies significantly across markets. Specifically, the stock market responds positively in Japan while negatively in Malaysia; Singapore and South Korea signal is unclear. We find that the stock market inefficiency, among others, appeared to have slowed the responses of the stock market to aggregate shocks such as oil price surges [10]. Sadorsky suggests that previous studies showed that oil prices and oil price volatility are often associated with inflationary pressure. Hence, oil prices are often indicative of future interest rates. Building on previous 、 studies and utilizing vector autoregression, Sadorsky concludes that oil prices and oil price volatility largely impact economic activities. In contrast, oil prices are not often impacted by economic activities. Sadorsky also suggests that positive shock in oil price positively impacts interest rate and industrial production because positive shock in oil prices and oil price volatility greatly impacted real stock returns. Additionally, oil price volatility shocks have asymmetric effects on the economy [11]. Jarrett et al. address the endogeneity issue by using periods of extreme oil price volatility as a source of nearly exogenous volatility to examine the effect of finance. They develop a quasi-natural experiment to study the mitigating role of financial depth in the impact of oil price volatility on growth. Using a synthetic control (counterfactual)method initially captures the degree to which financial depth mitigates the negative effects of oil volatility. To identify the dependence of financial markets on oil prices, they focus on measures that provide longterm institutional support for finance. And then use a cross-sectional augmented autoregressive distributed lag (CS-ARDL) approach to address any remaining endogeneity issues to test their results and eventually find them consistent. They finally draw their conclusion that a freer financial system has the flexibility to allow markets to adjust more quickly to fluctuations in oil and commodity prices, leading to better allocation of capital and steadier economic growth [12].

\subsection{Objective}

Motivated by the interest towards the correlation between the crude oil prices and the U.S. stock market return, the following study is conducted. This study hopes to determine the degree or condition of such correlation. Thus, historical data regarding oil price and U.S. stock market return are analysed.

\section{DESCRIPTION}

\subsection{US stock market development trend}

In recent years, financial markets have grown increasingly important to a country's long-term economic development, effective financing and tangible capital formation. As an essential part of the financial market, the stock market has a great influence on promoting the growth of the national economy and the integration of the world economy. According to the Dow Jones Theory, the stock market is the economic barometer, the most classic summary of the stock market.

In terms of the US stock market, due to the financial crisis, the US stock market plummeted until early 2009, following the financial crisis, which hit its lowest point. However, from that point, the US stock market has been on a decade-long term rise, hitting an all-time high in 2021. It can be illustrated through these three indexes. For example, as shown in Figure1, S\&P 500 dipped as low as 666.80 following the financial crisis, then it's been going up for 12 years, and it climbed to a record high of 4,533 points (2021). Dow Jones fell to $7,949.09$ points, which is the lowest inaugural performance. In the following years, it rose to new highs. It reached an alltime high in 2021, approximately 34200 points. The techheavy Nasdaq also followed the same pattern, and it reached a fresh high of 15,355 points (3rd September 2021) due to the impressive corporation profitability.

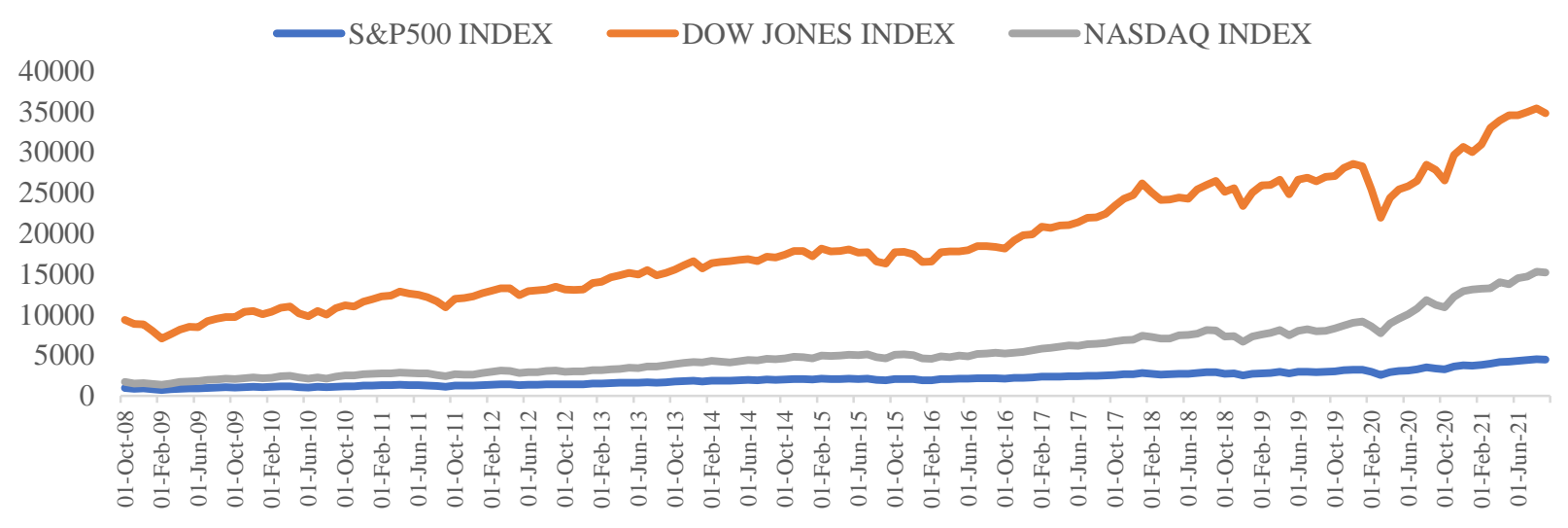

Figure 1 Thirteen years of S\&P 500, Dow Jones Index, Nasdaq Index (2008-2021) 
The S\&P 500 hit record highs in 2021, with oil and travel-related stocks extending gains. 7 of 11 the S\&P's major sectors rose. Energy stocks are one of the major sectors. The US stock price rose sharply over these 12 years. This may raise concerns about the reasons for the higher growth among the US stock market. In fact, the stock price is determined by various factors. For instance, supply and demand, operation of listed companies, other financial products, the influence of the overall economy etc. However, these factors are divided into three categories: fundamental, technical, and market sentiment

Primarily, the stock price can be measured through $\mathrm{P}=\mathrm{EPS} * \mathrm{PE}$. This is because earnings per share (EPS) in the US is growing. Changes in the Earnings per share growth rate, which is the acceleration or deceration of earning per share, influence the stock price. PE ratio related to the interest rate. According to Figure2 below shows that US 10-year Treasury bonds have been falling over time, indicating that US interest rates remain historically low. Therefore, the long-term rise of the US stock market has been related explicitly to the low interest rates in the US. The Quantitative easing policy in the US keeps interest rates low to stimulate the economy, increasing consumption and investment, leading to the US stock market rising.

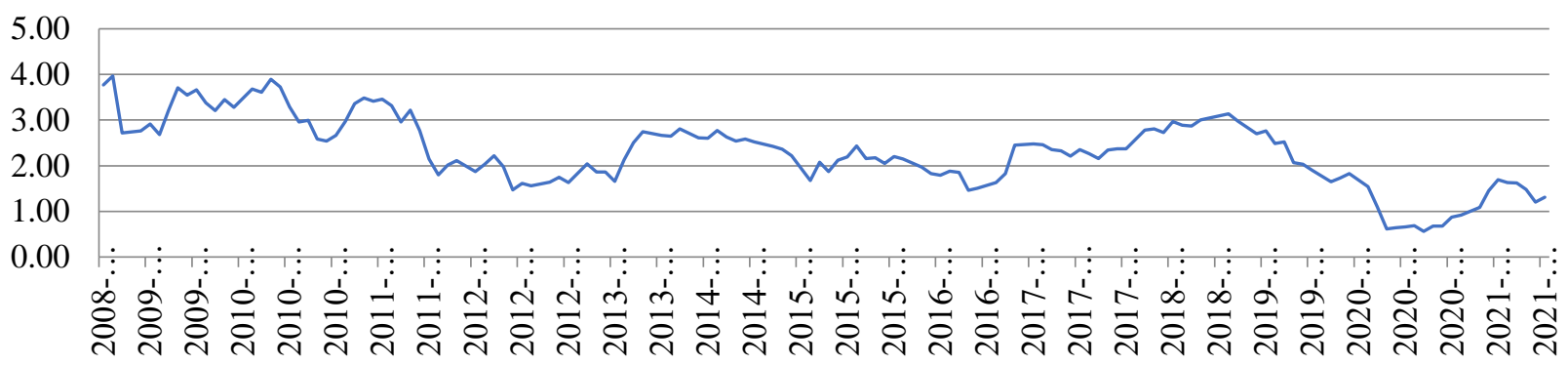

Figure 2 US Ten years Treasury Notes (Monthly)

\subsection{Reason of oil market price fluctuating}

Three aspects will influence the price fluctuating in the crude oil. First, the oil satisfies the laws of the supply and demand curve in the economy like the other commodity, stock, or bond. In the demand-supply curve, when people show more demands for oil, the equilibrium point will move to the right and cause the price to increase. By contrast, if the demand for oil decreases, the equilibrium point will move to the left and decrease the oil price. The next reason for oil prices fluctuating is technology innovation. When people invent new techniques, like new equipment for crude oil refining and transporting technology, the cost of crude oil production will decrease. Those areas where oil is exploited have the opportunity to produce more oil by reducing oil prices around the world. The final factor for oil price fluctuation is the game between governments of the world's major countries and the political situation between those countries. For example, in 2020, Saudi Araba engaged in an oil price war with Russia. It led to a huge fluctuation in the international oil price, with U.S. oil prices down 34 per cent, crude oil prices down 26 per cent, and Brent crude oil prices down 24 percentage. In conclusion, technology innovation only will decrease the oil price in the market. However, the first and third factors can lead the crude oil price to fluctuate in the market.

\subsection{Why US stock market is related to the oil market}

In brief, the relationship between international oil prices and the US stock market is influenced through certain processes. First, the alternation of international oil price would influence consumption, production, investment, and trade in economic operation, resulting in GDP and corporations' profits. Thus, corresponding stock prices experience fluctuation, and the whole stock market is impacted. Moreover, the rise in international oil prices promotes the cost for corporations' production and inflation rate, which leads to reduced currency supply and further triggers economic growth to slow down. Meanwhile, by forcing corporations to purchase more expensive raw material, oil, the performance of individual firms in the stock market is also influenced.

\section{THE RELATIONSHIP BETWEEN THE US STOCK MARKETS WITH THE CRUDE OIL PRICE VOLATILITY}

This study analyses the impact of oil prices on the US stock markets. To investigate the overall shape of the US stock market, we chose to study the S\&P 500 data and analyze whether those single data is correlated with the oil price. An increase in oil prices usually lowers the expected return for companies with the higher cost of 
production and lower the national economy's economic growth, or may lead to inflationary pressure in the overall economy in the short term. Specifically, decreasing economic growth would lead to a fall in business confidence associated with animal spirits, resulting in a dampening effect on stock prices and vice versa.

\subsection{Corporate profits}

As a commodity, crude oil plays a vital role in the real economy and the financial market. In addition, crude oil is a global commodity that trades in markets across the globe, which is a key source for energy production.
The US is the most industrial country globally, with a significantly high demand for crude oil. Oil prices hit record highs of $\$ 147$ a barrel in 2008 , but as the global financial crisis began to bite along with the supply and demand pressure, it plummeted to around \$30.The continuously declining price of crude oil will lower the production costs for firms, leading to a rise in business profits, thereby affecting the stock price. Figure 3 reveals that the S\&P500 Earning Per Share constantly rising from 2008 to 2021 . The overall upward trend indicates that the business revenues are rising at an increasing rate over time, as shown in Figure 3.

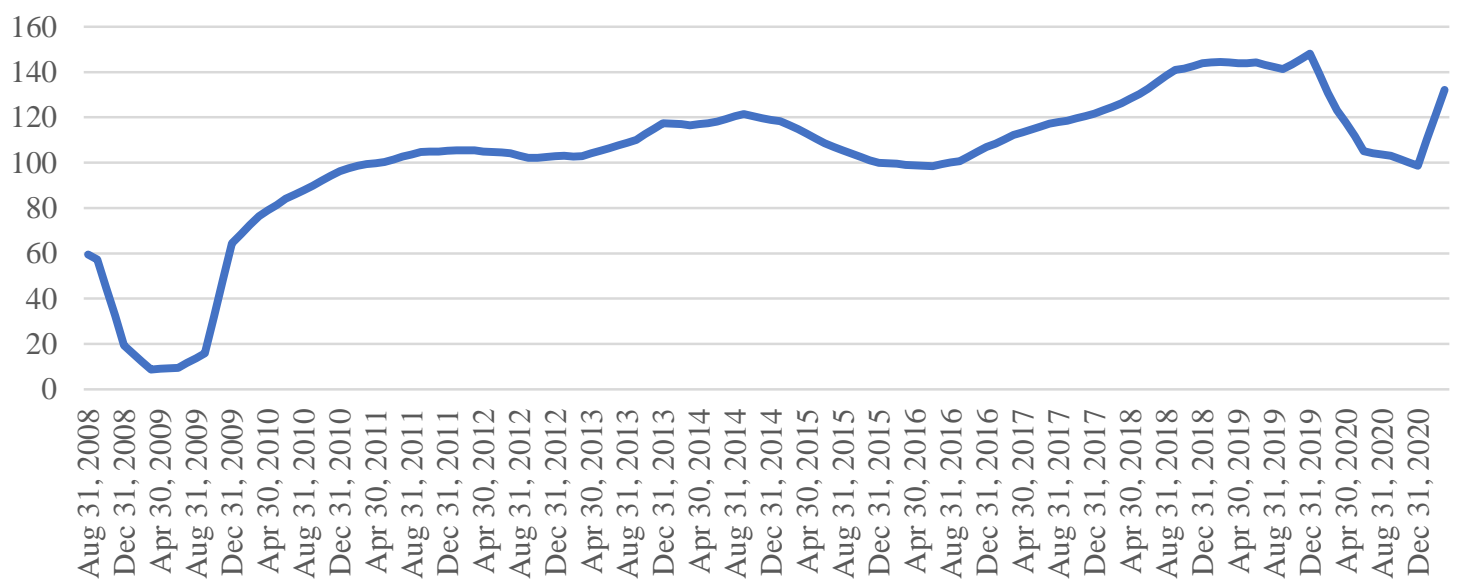

Figure 3 S\&P500 Index EPS(Monthly)

\subsection{Interest rates}

Since the 2008 financial crisis, there has been a fluctuating downward trend with evident overall volatility in oil prices (Figure4). Price changes in the commodity can affect the economic ecosystem at every level. The decline in oil price and the commodity market price and the CPI\&PPI data especially indicates that there is no inflationary pressure on the American national economy, which bolster the Federal Reserve kept the interest rates low. To stimulate the economy over the past decade, they have adopted a continuous low-interest monetary policy, quantitative easing, which has caused the US Treasury notes to fall for over 12 years. Therefore, the low interest rate and the low discount rate increase the company's cash flow and US stock price.

A combination of lower costs and higher profits for US companies, coupled with higher earnings and lower discount rates, has led to a surge in US stock prices. In addition, within the low-interest-rate environment, some US big companies began to buy back their shares to raise their earnings per share, which, therefore, pushed up the stock price.

\subsection{Correlation in opposite trend: COVID-19}

Over the past decade, low oil prices have been boosting corporate profits and supporting the Federal Reserve's policy of keeping interest rates low, which has kept the US stock prices continuously high.

In 2020, the coronavirus pandemic resulted in a depression in the economy, the oil demand fell sharply, which led to the crude oil prices hit a major slump. However, the US economy began to recover in most sectors since later 2020. The oil price picked up considerably, doubled from the pandemic level, from $\$ 30$ to nearly $\$ 70$ recently, associated with the rising demand within the oil market and the quantitative easing implemented in the US. The sharp drop in the interest rate and discount rate leads to an increase in inflation, from $2 \%$ to $5 \%$ approximately. These indeed caused the soared in the price of the commodity market in general. In July, the CPI index rose 5.4\% over the last 12 months, reached 273 . In this case, the stock market is at risk of a correction. 


\subsection{How do oil prices affect the U.S. stock market performance?}

The price of crude oil does not affect stocks directly, but it will be indirectly transmitted and affect the U.S. stock market. Since corporate earnings and interest rate $\mathrm{P}=\mathrm{EPS}$ determine stock prices*PE, oil prices could affect those two aspects as aforementioned, and therefore, it affects the US stock market. The total market and the stock price performances during periods of fluctuations of oil prices are consistent with the expectation that a fall in oil price will positively affect the stock prices via their impact on the outlook for the company's EPS and vice versa. In addition, oil is also a proxy for commodities. The rise in oil price will lead to the overall rise in the commodity market, leading to inflationary pressure on the national economy. Therefore, the Federal Reserve would regulate prices by raising interest rates and discounting rates, which tend to negatively affect earnings and stock prices.

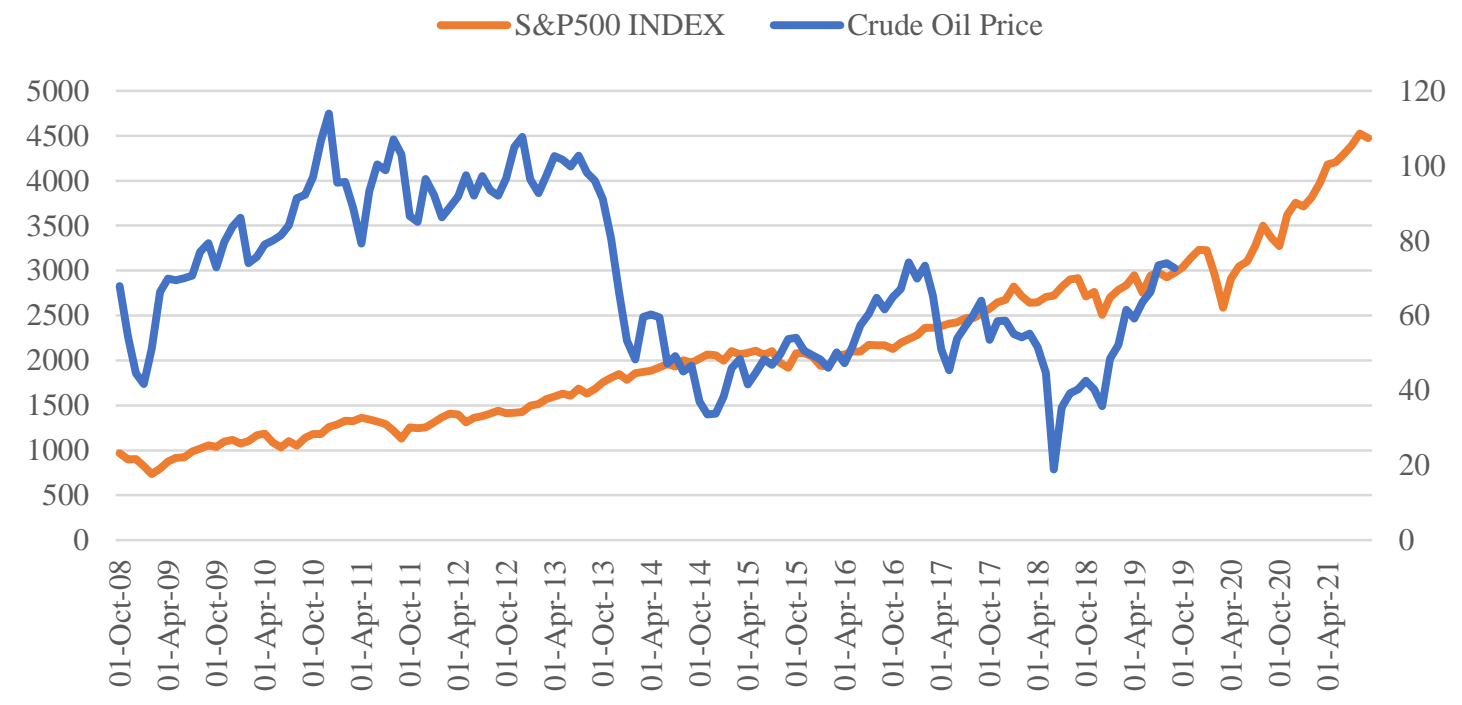

Figure 4 Correlation between S\&P500 and Crude Oil Price

By way of evaluation, we could find that there are some limitations to our methodology. First, reality suggests that there is sometimes little correlation between oil prices and stock market performance. For instance, when those market participants have high expectations over the stock market, the prices are determined entirely by those market expectations due to the animal spirits instead of crude oil. Also, since the oil price itself is subject to supply and demand and world political and economic developments, the stock market is influenced by the macroeconomic market environment, government policies and other market forces. So there is some correlation between the two, but they have their independent pricing direction; the correlation indeed is not so strong. Meanwhile, the development of new energy in recent years has weakened people's demand for crude oil. Therefore, the influence of crude oil will be diminished accordingly, and the correlation between the cost and price of crude oil and corporate earnings will be reduced, which will be reflected in the US stock market.

\subsection{Market expectations}

The continuous increase in inflation leads to a rising concern in the market that the Fed may raise interest rates as a result. Generally speaking, if oil prices continue to rise and inflation remains high, the Federal Reserve will thus adopt the contractionary monetary policy. Inflation will therefore be under control due to the rising interest rate, and the overall stock market will also adjust to a reasonable position from the current record high. Additionally, as the production capacity of crude oil will increase along with the supply chain's rise, the supply and demand will continue equilibrium over time, which makes the price of oil in the future expect to reach stable volatility.

\section{EVIDENCE-PERIOD}

This study analyses the relationship between stock prices and crude oil prices during the financial crisis in 2008, 2010-2011, and the oil war in 2020.

\subsection{The Financial Crisis Contrasts}

The time for this set of evidence is locked during the financial crisis. After obtaining the data at the time, a comparison table was made. In Figure 5, the highest and lowest values of stock and oil prices during the financial crisis were compared. Combining the data from the two charts, it can be seen that from February 6, 2009, to March 28, 2009, the stock continued to fall for many days, 
but compared with oil prices, it did not decline but continued to grow or maintain constant.

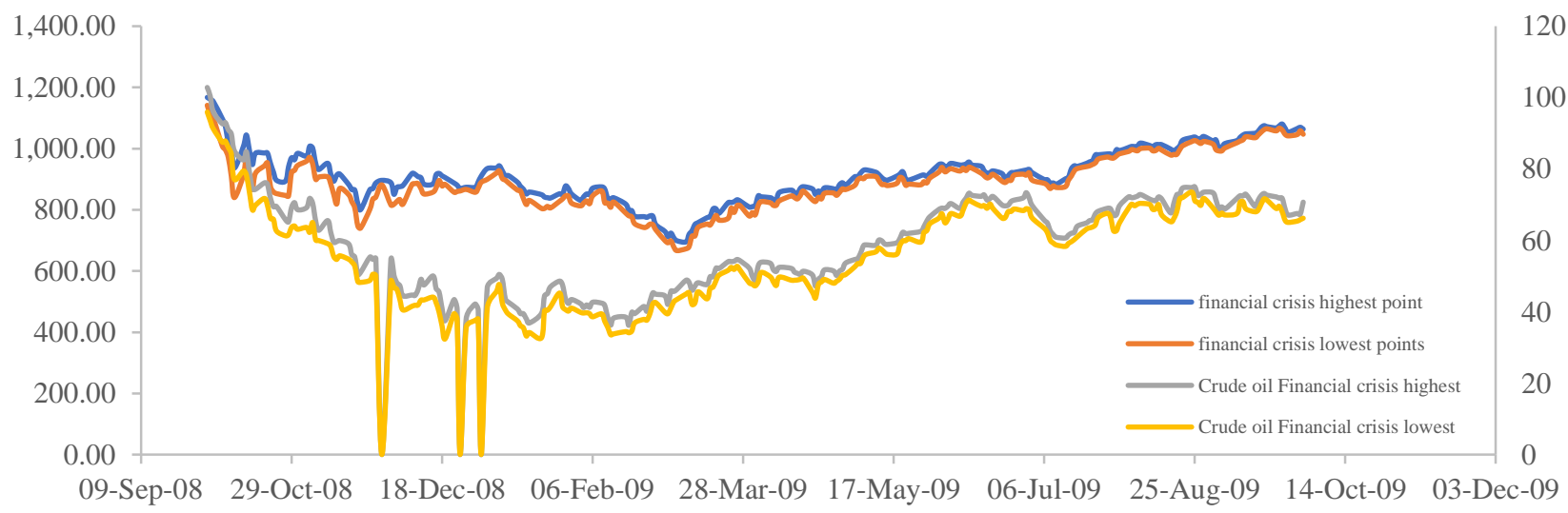

Figure 5 Financial Crisis highest and lowest S\&P500 vs Crude Oil Data

\subsection{Random Sampling}

The next two sets of charts (Figure 6) will show the data for a year that we randomly selected. The time points of these two sets of pictures are 2010-2011, respectively. According to the chart during the financial crisis, we have concluded that when the value of the stock drops, the price of crude oil will rise or remain unchanged, but in these two sets of data, we can see that no matter how large the stock data changes, crude oil The price will not have a large margin. In a year, sometimes the price of stocks will increase, and the price of crude oil will increase or remain the same, but sometimes when the price of stocks decline, the price of crude oil will still increase or remain the same.

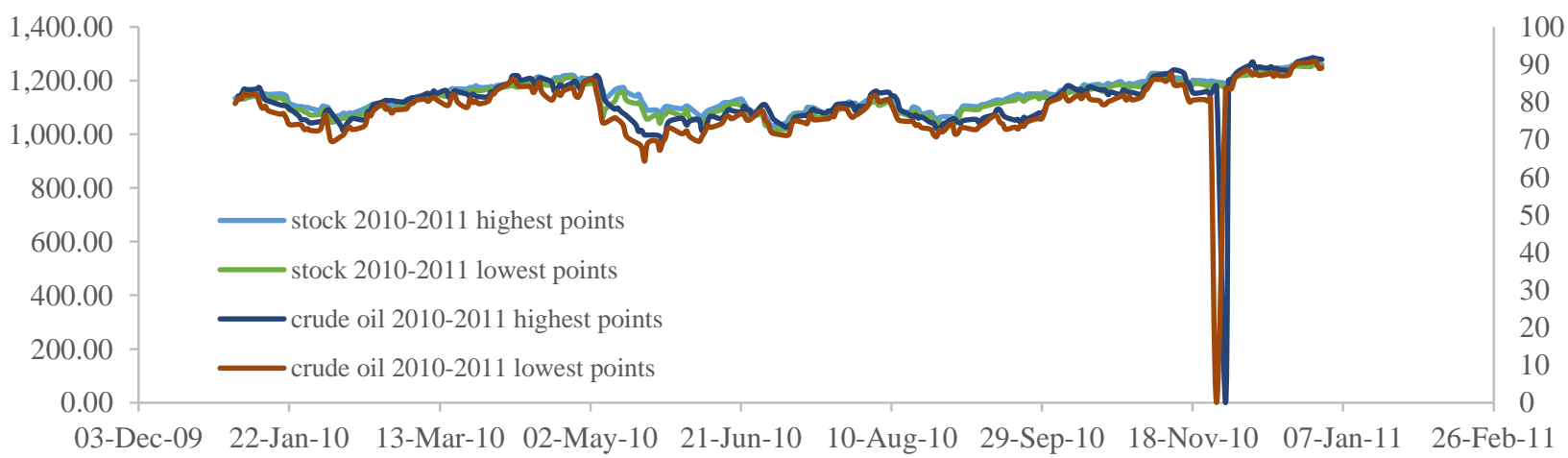

Figure 6 2010-2011 highest and lowest S\&P500 vs Crude Oil Data

\subsection{Small-scale analysis}

In our stock data and crude oil data, the highest value from January to March 2010, are selected and put in a graph for comparison (Figure 7). According to this graph, it is obvious that the stock rose by one day on February 1, 2010, and then The other four days have maintained a downward trend, but crude oil prices have been different. For example, in the first four days of this week, the price of crude oil remained almost at a constant value, but it fell on the fifth day. 


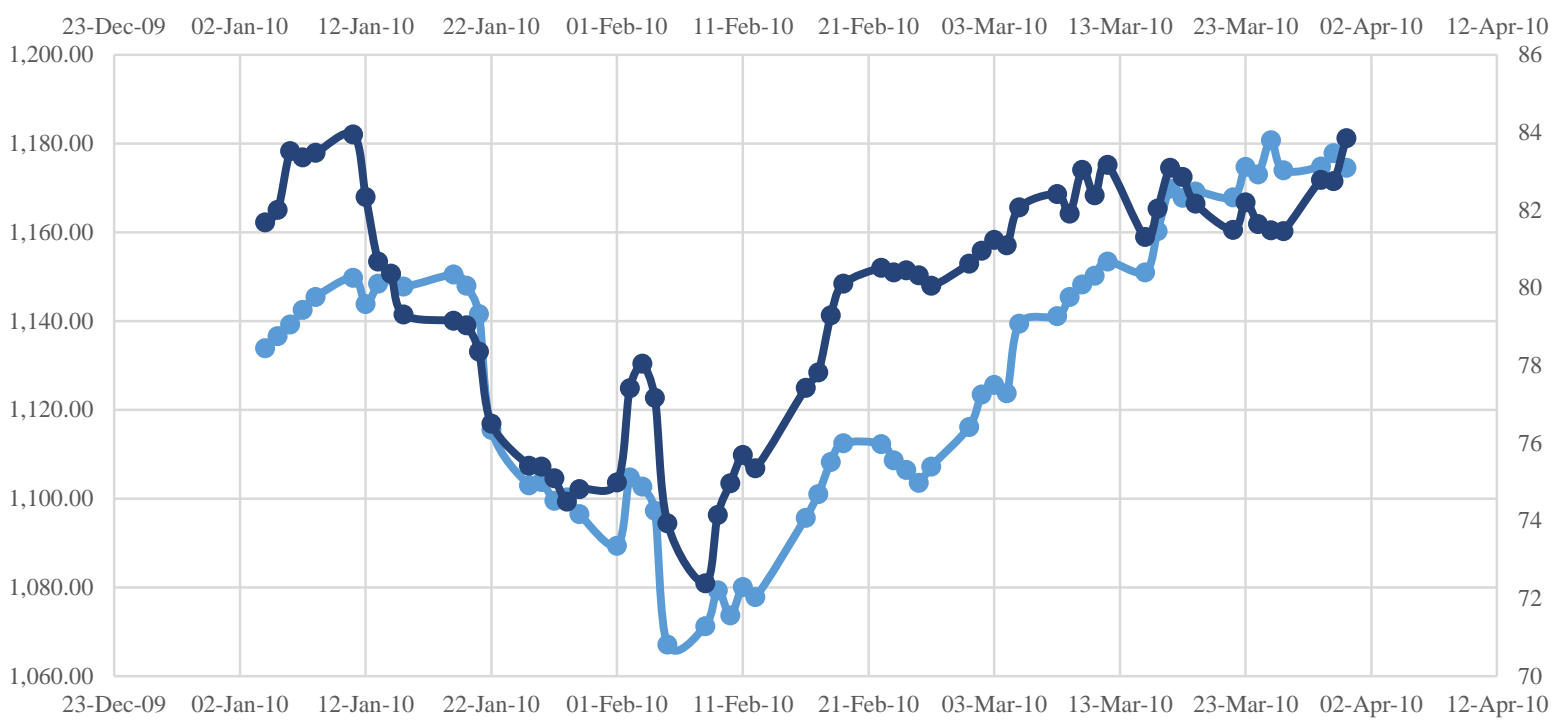

Figure 7 January to March 2010 highest S\&P500 vs Crude Oil Data

Additionally, through analyzing crude oil price and the S\&P500 index during the oil war in 2020, crude oil price turns out to be irrelevant to the US stock market. The oil war in 2020 began when the Energy Minister of Russia rejected the Energy Minister of Saudi Arabia of oil production deduction proposal. Saudi Arabia initially intended to collude with all OPEC and OPEC + members to conduct a reduction plan of 1500 thousand barrels per day to maintain crude oil price. However, considering that such a reduction plan would benefit the production of shale oil mainly controlled by the United States, Russia refused to conduct the plan. Subsequently, Saudi Arabia, the proposer of the reduction plan, immediately decided to increase production, thus shrink crude oil price. At the beginning of March, when Saudi Arabia was ready to conduct a reduction plan, crude oil prices raised. Two weeks later, after the rejection from Russia, the oil war broke, and oil prices dropped dramatically.

In contrast, the performance of the US stock market indicated by the S\&P500 index does not correspond with the turbulence in the crude oil market brought by the oil war. The lowest point during that period was between February and March, before the broke of the oil war. What's more, oil prices experienced a rise and dropped during March, while the S\&P500 index showed the trend of steady increase. Thus, turbulence in crude oil price accompanied by the steady increase in US stock market, such scene illustrates Oil war and dramatic change in crude oil price seemed to have little impact on US stock market.

\section{CONCLUSION}

This research establishes the comparison between the historical data of oil price and that of the U.S. stock market return and finds that there is no direct correlation between crude oil price and U.S. market prices. But crude oil price can affect a firm's business revenues and U.S. interest rate by influencing the CPI and PPI index, thus providing an indirect relationship between crude oil price and the U.S. stock market performance. This effect is more pronounced and effective, especially when oil prices are unstable. Since the oil price affects every aspect of the economy, including macroeconomic indicators and corporate decisions, every fluctuation in oil price can affect the oil market's production and consumption, which indeed affects the world inflation trend. Moreover, stocks exist in the world economy and are therefore influenced by it. This research provides professional analysis to help enterprises make profits according to the changing oil prices and plan their future development effectively.

\section{REFERENCES}

[1] Kilian, L., \& Park, C. (2009). The impact of oil price shocks on the US stock market. International Economic Review, 50(4), 1267-1287.

[2] Hedi Arouri, Mohamed El \& Khuong Nguyen, Duc, 2010. "Oil prices, stock markets and portfolio investment: Evidence from sector analysis in Europe over the last decade," Energy Policy, Elsevier, vol. 38(8), pages 4528-4539, August. 
[3] Syed, S. A. S., \& Zwick, H. S. (2016). Oil Price Shocks and the US Stock Market: Slope Heterogeneity Analysis. Theoretical Economics Letters, 6(3), 480-487.

[4] Demirer, R., Ferrer, R., \& Shahzad, S. J. H. (2020). Oil price shocks, global financial markets and their connectedness. Energy Economics, 104771. doi:10.1016/j.eneco.2020.104771

[5] Sim, N., \& Zhou, H. (2015). Oil prices, US stock return, and the dependence between their quantiles. Journal of Banking \& Finance, 55, 1-8.

[6] Heidari, H., Ebrahimi Torki, M., \& Babaei Balderlou, S. (2015). How Do Different Oil Price Shocks Affect the Relationship Between Oil and Stock Markets?.

[7] Mohanty, S. K., Nandha, M., Turkistani, A. Q., \& Alaitani, M. Y. (2011). Oil price movements and stock market returns: Evidence from Gulf Cooperation Council (GCC) countries. Global Finance Journal, 22(1), 42-55.

[8] K. S. Musa et al (2020). COVID-19 Pandemic, Oil Price Slump and Food Crisis Nexus: An Application of ARDL Approach. Open Access Library Journal. PP. 1-19.

[9] Mugaloglu, E., Polat, A. Y., Tekin, H., \& Dogan, A. (2021). Oil Price Shocks During the COVID-19 Pandemic: Evidence From United Kingdom Energy Stocks. Energy RESEARCH LETTERS, 2(1).

[10] Le, T. H., \& Chang, Y. (2011). The impact of oil price fluctuations on stock markets in developed and emerging economies.

[11] Sadorsky, P. (1999). Oil price shocks and stock market activity. Energy economics, 21(5), 449-469.

[12] Jarrett, U., Mohaddes, K., \& Mohtadi, H. (2019). Oil price volatility, financial institutions and economic growth. Energy Policy, 126, 131-144 